\title{
Aplicação do eugenol como antioxidante natural em biodiesel de soja e de microalgas.
}

\author{
Matthieu Tubino (PQ), Willian L. G. da Silva (PG), Acacia A. Salomão (TM), Rodrigo G.Cuyumiian (IC)
}

\section{Resumo}

O eugenol foi utilizado como aditivo em biodiesel de soja e de microalgas para aumentar a estabilidade à oxidação. O Período de Indução $(\mathrm{Pl})$ do biodiesel isento e acrescido de eugenol foi determinado seguindo a norma EN 14112. Os resultados indicam que o eugenol apresenta efeito antioxidante aumentando em 1 hora o PI do biodiesel de soja e de microalgas além disso, mantém o PI acima do mínimo permitido (8 h) por um período de 60 dias.

Palavras Chave: Biodiesel, eugenol, estabilidade à oxidação.

\section{Introdução}

O uso em larga escala da energia proveniente da biomassa pode contribuir para o desenvolvimento sustentável nas áreas ambiental, social e econômica. O biodiesel obtido de fontes renováveis, tais como óleos vegetais, gordura animal e óleo de microalgas é uma aplicação da biomassa para produção de energia.

Uma desvantagem do biodiesel é sua baixa estabilidade à oxidação podendo sofrer influência do ar, altas temperaturas, traços de íons metálicos, luz, umidade e contaminação microbiológica ${ }^{1}$. Neste contexto aditivos com ação antioxidante são necessários para garantir a qualidade desse biocombustível. A ANP (Agência Nacional de Petróleo, Gás Natural e Biocombustíveis) estabelece um Período de Indução (PI) mínimo de $8 \mathrm{~h}$. O PI é definido como o tempo necessário, à $110^{\circ} \mathrm{C}$, para que iniciem os processos de oxidação, com a formação de compostos voláteis.

Neste trabalho utilizou-se o eugenol que pode ser obtido do cravo da Índia (Caryophyllus aromaticus) $^{2}$ como aditivo em biodiesel provenientes de óleos de soja e de microalgas.

\section{Resultados e Discussão}

O biodiesel foi sintetizado a partir da reação de transesterificação de óleos de soja e de microalgas com metanol na presença de metóxido de sódio como catalisador, sob agitação de $900 \mathrm{rpm}$ e aquecimento à $60^{\circ} \mathrm{C}$. Após processo de purificação que envolve lavagem com água destilada à $60^{\circ} \mathrm{C}$, secagem em estufa à $100^{\circ} \mathrm{C}$ e uso de resina de troca iônica, adicionou-se ao biodiesel $0,5 \%(\mathrm{~m} / \mathrm{m})$ de eugenol para posterior determinação do $\mathrm{PI}$, seguindo a norma EN 14112. A Tabela 1 mostra os valores do PI do biodiesel de soja e de microalgas isentos e acrescidos com eugenol.
Tabela 1. Avaliação do potencial antioxidante do eugenol .

\begin{tabular}{|c|c|c|}
\hline $\begin{array}{c}\text { Concentração } \\
(\% \mathrm{~m} / \mathrm{m})\end{array}$ & $\begin{array}{c}\text { Biodiesel de } \\
\text { Soja }\end{array}$ & $\begin{array}{c}\text { Biodiesel de } \\
\text { Microalgas }\end{array}$ \\
\hline 0 & $5,7 \pm 0,1$ & $8,4 \pm 0,3$ \\
\hline 0,5 & $6,7 \pm 0,2$ & $9,43 \pm 0,08$ \\
\hline
\end{tabular}

Após a verificação do potencial antioxidante do eugenol realizou-se um monitoramento da estocagem por cerca de 110 dias. A Figura 1 indica os resultados obtidos para o biodiesel de microalgas.

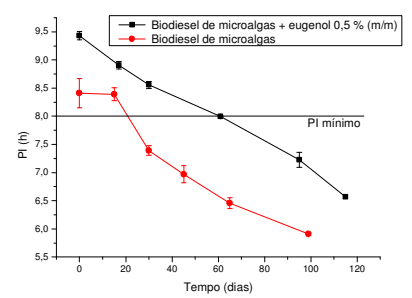

Figura 1. Variação do $\mathrm{Pl}$ do biodiesel de microalgas em função do tempo de estocagem à temperatura ambiente.

\section{Conclusões}

Os resultados obtidos comprovam que o eugenol apresenta atividade antioxidante. A associação desse composto ao biodiesel de soja e de microalgas eleva o PI garantindo a qualidade desses biocombustíveis.

\section{Agradecimentos}

Ao CNPq pelo financiamento do projeto e ao Instituto de Química pela infraestrutura oferecida.

\footnotetext{
Serrano, M.; Oliveros, R.; Sánches, M.; Moraschini, A.; Martínez M. e Aracil, J. Energy 2014, 65, 109.

Oliveira, R. A.; Oliveira, F. F. e Sacramento, C. K. Bahia Agric 2007, 8, 46 .
} 